\title{
COVID-19's SHORT-TERM IMPLICATIONS, CHALLENGES ON TERTIARY INSTITUTIONS AND WILLINGNESS TO ADOPT E- LEARNING: INSIGHT FROM TOMPI SELEKA COLLEGE OF AGRICULTURE, SOUTH AFRICA
}

(D) Vuledzani Sheryl
Magadane $^{1}$
(iD) Agboola Peter
Temitope $^{2+}$
(D) Oluwaseun Samuel
Oduniyi $^{3}$
(iD Lebogang Lucky
Aphane $^{4}$

Received: 29 December 2020 Revised: 13 May 2021 Accepted: 11 June 2021 Published: 28 June 2021

\section{Keywords}

COVID-19 pandemic E-learning

Tertiary institutions PCA

Binary regression model.
${ }^{\prime}$ Tompi Seleka College of Agriculture, Limpopo Department of Agriculture, Marblehall, South Africa.

Email:sherylvule@gmail.com Tel:+27790765041

${ }^{2}$ Sam Houston State University, School of Agricultural Sciences, Huntsville, Texas, USA.

Email:teetop32000@gmail.com Tel:16822184776

${ }^{3}$ Department of Agriculture and Animal Health, University of South Africa, Unisa Science Campus, South Africa.

Email:eodunios@unisa.ac.za Tel:+27739987498

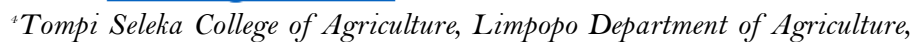
Marblehall, South Africa.

Email:leboganga20@gmail.com Tel:+27606149364

(+ Corresponding author)
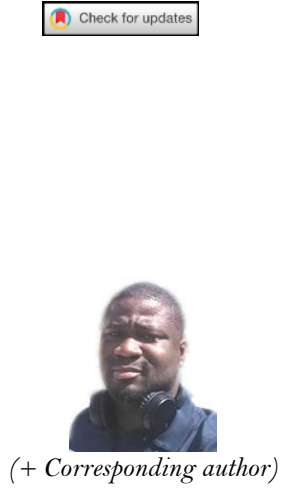

ABSTRACT

COVID-19 is a contagious disease that originated from Wuhan City, China. Today, it has spread to over two hundred countries in the world leading to a total or partial lockdown in most countries, including South Africa. Consequently, the lockdown has negatively impacted every functional aspect of humanity, including education. While studies abound on its medical, social, and psychological implications, there is a dearth of research on its implications on education, the challenges and uncertainties experienced by the students, particularly in South Africa's tertiary institutions. These uncertainties triggered institutions to find alternative means and approaches to continue learning; thus, online teaching is considered a sui generis method. Therefore, this study is aimed at exploring the challenges faced by students at Tompi Seleka Colleges of Agriculture during the lockdown and further explores their willingness to adopt E-learning as their new method of teaching and learning. The study adopted a quantitative design whereby principal component analysis and binary logistics regression model were used to estimate the challenges and the influencing factors to adopting E-learning. Students were found to be facing various challenges during the COVID-19 lockdown, ranging from the uncertainty about the future of their studies, adjusting from their traditional way of teaching and learning to self-study and E-learning. The finding showed that $37 \%$ of the students are willing to adopt E-learning. The study recommends that the significant challenges and determinants should be put into consideration for effective adoption of E-learning in tertiary institutions in the college, and South Africa at large.

Contribution/ Originality: This study is one of the very few studies which have investigated the implications of covid-19 at college education while other studies focused more on university education. The papers primary contribution is finding that college institutions can adopt hybrid mode of teaching which comprise both online and face-to-face in order to carter for both theoretical part and practical. 


\section{INTRODUCTION}

Coronavirus is a highly infectious viral disease (World Tourism Organization, 2020), it was discovered recently in the city of Wuhan, China in December 2019. Subsequently, COVID-19 was declared a global pandemic by the World Health Organization because of its rapid spread to over two hundred countries, Pelmin (2020); World Tourism Organization (2020). Following its globality, virtually every affected nation invented ways to curb the uncontrollable spread of the deadly disease. Some of the precautionary measures adopted by the different governments are social distancing, partial or total lockdown, and wearing of face mask. For instance, South Africa reported its first case of the coronavirus on the $5^{\text {th }}$ of March 2020 and have since recorded over 197000 according to National Institute of Communicable Disease, South Africa, 2020. This has however led to a national state of disaster, leading to the implementation of a national lockdown by the president. As a result, virtually every functional aspects of the nation's socioeconomic and socio-political sphere is at a standstill, including individual livelihood (World Tourism Organization, 2020).

Moreover, the educational sector has been grossly affected by the widespread of the pandemic and has consequently led to the closure of all institutions of learning: primary, secondary, and tertiary. According to UNESCO (2020), coronavirus has affected over 1.5 billion students and youth across the globe because of the widespread closures of schools. As a result of the lockdown teachers are compelled to adopt the online (E-learning) style which seems to be the only plausible alternative, since the traditional face-to-face mode of teaching is no longer possible. However, this adoption is very complex in the African continent where approximately only $24 \%$ of the populace have access to internet, not mentioning the challenges of poor connectivity, exorbitant costs and frequent power interruptions, making it difficult to establish e-learning (UNESCO, 2020).

For instance, in South Africa, widespread and viable internet connection is only evident in the major cities, while the rural communities are left with little or no access to internet. So, it is patent that the implementation of Elearning in tertiary institutions in South Africa will only benefit academic institutions and students residing in the urban areas, while tertiary institutions and students in the rural communities will undoubtedly make do with poor internet connectivity and interrupted power supply. Thus, it cannot be gainsaid that these constrains are bound to affect the learning of the students in these rural communities negatively. It follows that this inequality in terms of infrastructure and resources among colleges and universities in South Africa will make the reality of online learning practically impossible. This is in line with Gedye (2020) discovery that in panicky situations, tertiary institutions have the tendency of sacrificing good educational standard just to ensure the completion of the first semester curriculum so as to duly commence the second semester, which is actually detrimental to a good and basic standard of learning.

It is apparent that majority of public colleges in the country lack the resources for online teaching. Therefore, there is need for tertiary institutions to identify the underlying challenges faced by students during the lockdown and help direct them on how to implement better risk management and coping strategies (catch-up plan) to better education. In addition, although E-learning is considered as the alternative solution to continuous learning during the pandemic, it is significant to understand the views and response of the students towards it. Hence, this study uncovers the challenges faced by students at Tompi Seleka College of Agriculture during the lockdown and their willingness to adopt E-learning as their new method of teaching and learning.

\section{METHODOLOGY}

\subsection{The Study Area}

The study was conducted at Tompi Seleka Colleges of Agriculture situated in Limpopo Province of South Africa as shown in Figure 1. The college was established in 1958 formally known as Arabie College of Agriculture, until it was renamed after the honourable Kgoshi ZT Seleka. The college is situated along the Olifants River in 
Marble Hall (near Phetwane village) in the Sekhukhune District. Tompi Seleka College is one of the twelve agricultural colleges in South Africa which is under the Department of Agriculture and Rural Development.

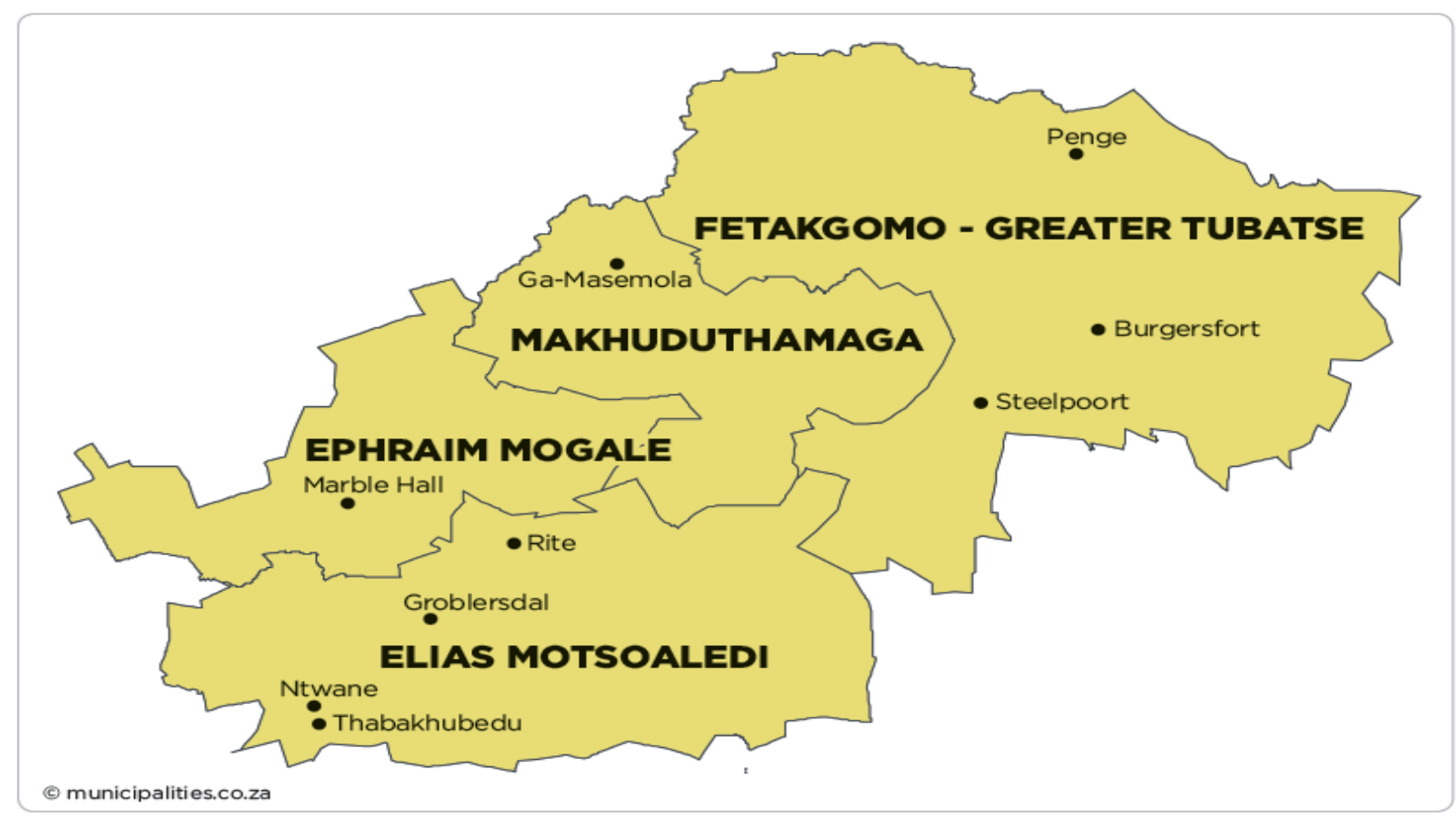

Figure-1. Geographic location of the greater Sekhukhune and Capricorn district in Limpopo province. Source: StatsSA (Statistics South Africa) (2008).

\subsection{Data Collection and Procedure}

Primary data was collected from the students at Tompi Seleka College of Agriculture using a questionnaire containing semi-structured questions based on the objectives of the study. The questionnaire contained challenges faced by students during the lockdown period and their willingness to adopt E-learning. The questionnaire was pretested and validated to avoid ambiguities and misinterpretation of the questions on the questionnaires. All the students were purposively selected to be part of the respondents; nonetheless, 81 students out of 116 voluntarily completed the questionnaire.

\subsection{Data Analytical Techniques}

To ensure accuracy, consistency, and uniformity, the data collected was edited, coded, and cleaned. The data was entered into Microsoft Excel, coded, and transferred into STATA. Descriptive statistics such as means, median, minimum, and maximum values, frequencies, percentages, and standard deviations were used to describe the data. Multivariate analysis and the binary logistic regression model (BLRM) were used to identify and analyse challenges that influence the adoption of E-learning system.

\subsection{Model Specification}

Principal Component Analysis (PCA): PCA is a statistical procedure that uses an orthogonal transformation to convert a set of observations of possibly correlated variables into a set of values of linearly uncorrelated variables called principal components. The results of a PCA are usually discussed in terms of component scores, sometimes called factor scores or factor loadings. Data set can be deconstructed into eigenvectors and eigenvalues. An eigenvector is a direction while an eigenvalue is a number that shows how much variance there is in the data in that direction. The eigenvector with the highest eigenvalue is, therefore, the principal component, where the eigenvector with the lowest eigenvalue contains less information which cannot be retained. 
Mathematically, the transformation is defined by a set of p-dimensional vectors of weights or loadings: $w_{(\mathrm{k})}=$ $\left(w_{1}\right.$ $\left.w_{p}\right)_{(k)}$ that map each row vector $x_{(i)}$ of $\mathrm{X}$ to a new vector of principal component scores $t_{(i)}=$

$\left(t_{1}\right.$ $\left.t_{n}\right)(i)$

Given by $t_{k(i)}=x_{(i)}, w_{(k)}$ for $i=1, \ldots \ldots \ldots, n \quad k=1, \ldots \ldots \ldots \ldots \ldots \ldots \ldots \ldots \ldots, m$

Following Oduniyi (2018) assuming we are converting a set of original data set or variables into $\mathrm{X}_{\mathrm{j}}(\mathrm{j}=1,2, \mathrm{k})$ into a new set of uncorrelated variables called principal components, PCI $(\mathrm{I}=1,2 \ldots, \mathrm{k})$, which were linear combinations of original variables (Koutsoyiannis, 1979).

Consider the linear combinations

$$
\begin{aligned}
& P C_{1}=a_{11} X_{1}+a_{12} X_{2}+\ldots \ldots \ldots+a_{1 K} X_{K} \\
& P C_{2}=a_{21} X_{1}+a_{22} X_{2}+\ldots \ldots \ldots .+a_{2 K} X_{K} \\
& P C_{3}=a_{31} X_{1}+a_{32} X_{2}+\ldots \ldots \ldots+a_{3 K} X_{K} \\
& P C_{K}=a_{K 1} X_{1}+a_{K 2} X_{2}+\ldots \ldots \ldots+a_{K K} X_{K}
\end{aligned}
$$

Where $P C_{1}=$ the $i$ th principal component,

aij = component loadings (coefficients)

And $\mathrm{Xj}=$ original variables.

Thus, the linear combinations give rise to: first principal component $\left(P C_{1}\right)$ accounts for the maximum possible proportion of the total variation in the $\mathrm{Xj}$ 's, the second principal component $\left(P C_{2}\right)$ accounts for the maximum of the remaining variation (variance) in the $\mathrm{Xj}$ 's and so on. In this manner we have: var $\left(P C_{1}\right) \geq \operatorname{var}\left(P C_{2}\right) \geq \operatorname{var}\left(P C_{3}\right)$ $\geq \ldots \geq \operatorname{var}\left(P C_{P}\right)$, where var $\left(P C_{1}\right)$ expresses the variance of $P C_{1}$ in the data set being measured.

The Binary logistic regression (BLR): BLR analysis was chosen because of the dichotomous nature of the dependent variable, as it can take only two values that are either the student is willing to adopt or not. Therefore, the outcomes were given values as 1 (one) for adopting E-learning and o (zero) otherwise, thus giving rise to a binary dependent variable. The main advantage of the BLRM over other models of discrete and limited dependent variables is that it allows the analysis of decisions across two categories, allowing the determination of choice probabilities from different categories. In addition, its likelihood function, which is globally concave, makes it easy to compute. In BLRM, a single outcome variable $Y_{i}(i=1, \ldots, n)$ follows a Bernoulli probability function that takes on the value 1 with probability $P_{i}$ and 0 with probability $1-\mathrm{P}_{\mathrm{i}} \cdot \mathrm{P}_{\mathrm{i}} / 1-\mathrm{P}_{\mathrm{i}}$ and is referred to as the odds of an event occurring. $P_{i}$ varies over the observations as an inverse logistic function of a vector $X_{i}$, which includes a constant and $K$ explanatory variables. The Bernoulli probability function can be expressed as:

$Y_{i} \Theta \operatorname{Bernoulli}\left(Y_{i} / P_{i}\right)$ 
or

$$
\begin{gathered}
\operatorname{In}\left[\frac{P_{i}\left(Y_{i}=1\right)}{1-P_{i}\left(Y_{i}=1\right)}\right]_{=\operatorname{In}(\text { Odds })=} \alpha_{0}+\sum_{k=1}^{k} \beta_{k} X_{i k} \\
\text { Odds }=\left[\frac{P_{i}\left(Y_{i}=1\right)}{1-P_{i}\left(Y_{i}=1\right)}\right]_{e x p}\left[\alpha_{0}+\sum_{k=1}^{k} \beta_{k} X_{i k}\right]
\end{gathered}
$$

or

$$
=e^{\alpha+\sum_{k=1}^{k} \beta_{k} X_{i k}}=e^{\alpha_{0} *} \prod_{k=1}^{k} e^{\beta_{k} X_{k}}=e^{\alpha_{0}} * \prod_{k=1}^{k}\left(e^{\beta_{k}}\right)^{X_{k}}
$$

There are several alternatives to the BLRM that might be just as plausible in a particular case. However, as stated above, the BLRM is comparatively easy from a computational point of view. There are many tools available which can be used to estimate logistic regression models but in practice, the BLRM tends to work fairly well. If either of the odds or the log odds is known, it is easy to figure out the corresponding probability which can be written as:

$$
P=\left[\frac{o d d s}{1+o d d s}\right]=\left[\frac{\exp \left(\alpha_{0}+\beta^{\prime} X\right)}{1+\exp \left(\alpha_{0}+\beta^{\prime} X\right)}\right]
$$

The unknown $\alpha_{0}$ is a scalar constant term and $\beta^{\prime}$ is a $K$ x 1 vector with elements corresponding to the explanatory variables. In this study, the parameters of the model were estimated by maximum likelihood. This means that the coefficients that made the observed results most likely were selected. The likelihood function formed by assuming independence over the observations can be written as:

$$
L(\alpha, \beta)=\prod_{i=1}^{n} P_{x_{i}}^{Y_{i}}\left(1-P_{x_{i}}\right)^{1-Y_{i}}
$$

To random sample $\left(x_{i} y_{i}\right), i=1,2, \ldots, n$, by taking logs and using Equation 2, the log-likelihood simplified to:

$$
\operatorname{In}\left[L\left(\alpha_{0}, \beta\right)\right]=\sum_{i=1}^{n}\{y(\alpha+\beta x)-\operatorname{In}(1+\exp (\alpha+\beta x)
$$

The estimator of unknown parameter $\alpha$ and $\beta$ can be gained from the following equations by means of maximum- likelihood estimation.

$$
\begin{gathered}
\frac{\delta \operatorname{In}\left[L\left(\alpha_{0}, \beta\right)\right]}{\delta \alpha_{0}}=\sum_{i=1}^{n} \mid y_{i}-\frac{\exp (\alpha+\beta x)}{1+\exp (\alpha+\beta x)}=0 \\
\frac{\delta \operatorname{In}\left[L\left(\alpha_{0}, \beta\right)\right]}{\delta \beta_{0}}=\sum_{i=1}^{n} \mid y_{i}-\frac{\exp (\alpha+\beta x)}{1+\exp (\alpha+\beta x)}=0
\end{gathered}
$$

Since Equations 8 and 9 are non-linear, the maximum likelihood estimators must be obtained by an iterative process such as the Newto-Raphson or Davidson-Flecher-Powell or Berndt-Hall-Hall-hausman algorithm. A statistical model based on likelihood ratio (LR) was deemed appropriate. This ratio was defined as follows:

$$
L R=2\left(\log L_{R}-\log L_{U}\right)
$$

Where $\log L_{u}$ was defined as the $\log$-likelihood for the unrestricted model and $\log L_{r}$ was the $\log$-likelihood for the model with $k$ parametric restrictions imposed. The likelihood ratio statistic follows a chi-square $\left(\chi^{2}\right)$ 
distribution with $\mathrm{k}$ degrees of freedom. STATA was used to analyze the Binary Logistic Regression regarding the factors influencing the adoption of E learning.

\section{RESULT AND DISCUSSION}

\subsection{Demographic Profile}

The results on Table 1 showed that out of 81 students who were interviewed, majority (63\%) of them were between the ages of 21 and 25 , while $16 \%$ were above the age of 25 . About $64 \%$ of the respondents were female, while $35 \%$ were male. Moreover, $32 \%$ of the students were in their final year ( $3^{\text {rd }}$ year) while $24 \%$ and $25 \%$ were in their first and second year respectively. The results also evinced that a substantial number (73\%) of students were from rural areas, while only $9 \%$ were residing in urban area. Finally, the demographic statistics revealed that majority $(64 \%)$ of the students were coming from households of 4 to 7 members. Similarly, Table 2 explained the frequency distribution of various questions related to e-learning among the students.

Table-1. Demographic Profile of the students.

\begin{tabular}{l|c|c}
\hline Variable & Mean & Std. deviation \\
\hline Age1 & 23.012 & 3.534 \\
\hline Gender & 1.358 & 0.482 \\
\hline HHS 1 & 5.556 & 1.987 \\
\hline Settlement & 1.358 & 0.639 \\
\hline Diploma & 1.420 & 0.497 \\
\hline Level & 2.099 & 0.831 \\
\hline Allowance & 1.593 & 0.494 \\
\hline Bursary holder & 1.432 & 0.498 \\
\hline Smartphone & 1.062 & 0.242 \\
\hline Laptop & 1.654 & 0.479 \\
\hline E-learning will not accommodate all the students & 0.889 & 0.316 \\
\hline difficulties with network connection & 0.901 & 0.339 \\
\hline The college does not have enough resources for E-learning & 0.827 & 0.380 \\
\hline Students cannot afford data for E-learning & 0.938 & 0.242 \\
\hline Adjusting from full-time direct teaching to self-study will be difficult & 0.889 & 0.316 \\
\hline I prefer classroom teaching more than online & 0.877 & 0.367 \\
\hline Lockdown affects students' timeline for their future plan(s) & 0.926 & 0.264 \\
\hline
\end{tabular}

Table-2. Frequency distribution of students' response to random questions.

\begin{tabular}{|c|c|c|c|c|}
\hline Variables & Frequency & Percentage & Frequency & Percentage \\
\hline & \multicolumn{2}{|c|}{ (Yes) } & \multicolumn{2}{|c|}{$(\mathrm{No})$} \\
\hline Do you receive monthly allowance from home? & 33 & $41 \%$ & 48 & $59 \%$ \\
\hline Are you a bursary holder? & 46 & $57 \%$ & 35 & $43 \%$ \\
\hline Do you receive a stipend from your bursary? & $\mathrm{O}$ & $0 \%$ & 81 & $100 \%$ \\
\hline Do you own a smartphone? & 76 & $94 \%$ & 5 & $6 \%$ \\
\hline Do you own a laptop & 28 & $35 \%$ & 53 & $65 \%$ \\
\hline Are you studying during the lockdown? & 32 & $40 \%$ & 49 & $60 \%$ \\
\hline $\begin{array}{l}\text { Are you doing other academic activities such as } \\
\text { (Assignment, research, projects etc.)? }\end{array}$ & 31 & $38 \%$ & 50 & $62 \%$ \\
\hline $\begin{array}{l}\text { Are you academically in contact with your lecturers } \\
\text { during the lockdown period? }\end{array}$ & 20 & $25 \%$ & 61 & $75 \%$ \\
\hline Are you enjoying being on lockdown? & 5 & $6 \%$ & 76 & $94 \%$ \\
\hline $\begin{array}{l}\text { Do you think the academic year } 2020 \text { can still be } \\
\text { saved? }\end{array}$ & 53 & $65 \%$ & 28 & $35 \%$ \\
\hline $\begin{array}{l}\text { Do you think E-learning would be an effective } \\
\text { method of teaching and learning for colleges? }\end{array}$ & 30 & $37 \%$ & 51 & $63 \%$ \\
\hline
\end{tabular}




\subsection{Challenges Faced by Students during the Covid-19 Lockdown Period}

The results on Table 3 demonstrated nine major challenges faced by students during the coronavirus lockdown period. Challenge 1 was stress: The results illustrated that majority of the students $(70.4 \%)$ strongly agreed that it was stressful being on lockdown and $24.7 \%$ of the students agreed. Challenge 2 was low morale: $49.4 \%$ of the students agreed that their morale was low during the lockdown, while $34.6 \%$ strongly agreed. A ratio of 12.3 maintained a neutral position; 3.1 disagreed Challenge 3: The third challenge experienced by the students was the inability to study at home. As represented in Table 3, an aggregate of 34.6 strongly agreed that they were not able to study at home during the lockdown, while $40.7 \%$ agreed. $17.3 \%$ maintained a neutral stance, while a percentage of 1.2 disagreed.

This third challenge was advocated by a substantial number of students (60\%) who revealed that they were not studying at home and $62 \%$ who were not doing other academic activities during the lockdown. Challenge 4 was unconducive learning environment: While a ratio of, 32.1 agreed that the environment at home was not conducive for learning, a percentage of 29.6 strongly agreed; $27.2 \%$ were indifferent; $9.9 \%$ disagreed and 1.2 strongly disagreed. This could be attributed to the fact that $81 \%$ of the students were residing in household that had more than four members. Correspondingly, studies have proved that crowded household are more likely to cause disturbance to learning (Jain \& Mohta, 2019).

Challenge 5 was lack of family support: Furthermore, the results showed that the majority of students (39.5\%) disagreed that they lack family support in their studies during the lockdown while only $11.1 \%$ agreed with the statement. Challenge 6 was apprehension for the future of their studies: The study revealed that another major challenge faced by college students due to Covid-19 lockdown was the uncertainty about the future of their studies. Thus, $42 \%$ strongly agreed whereas $32.1 \%$ agreed that they were uncertain about the future of their studies, precisely those in their final year (39\%).

Their uncertainty can be ascribed to the fact that no one is certain when the nationwide lockdown will be over. Challenge 7 was the fear of losing their funding and bursary opportunities: About $35.8 \%$ and $22.2 \%$ of the students strongly agreed and agreed respectively that lockdown posed a fear to lose their funding and bursary opportunities. Challenge 8: Finally, $66.7 \%$ of the students strongly agreed that lockdown affected student's practical and research trials. Challenge 9: Finally, results show that most students $(64.2 \%)$ strongly agreed that they felt pressure to catch-up for lost academic time.

The results on Table 4 explained the mean and the standard deviation of each challenge faced by the students during the lockdown. The lack of family support was having a high mean as reported by the students, followed by fear of losing funding and unconducive environment to learn at home during Covid -19 lockdown, while the least challenge (lowest mean on Table 4) as pointed out by the students was stress.

Table-3. Statistical distribution of challenges faced by students during the Covid-19 lockdown period.

\begin{tabular}{l|l|c|c|c|c|c}
\hline Variable & description of the variables & $\begin{array}{c}\text { Strongly } \\
\text { Agree }\end{array}$ & Agree & Neutral & Disagree & $\begin{array}{c}\text { Strongly } \\
\text { disagree }\end{array}$ \\
\hline Challenge 1 $\left(\mathrm{X}_{1}\right)$ & Stressful & 70.4 & 24.7 & 4.9 & 0 & 0 \\
\hline Challenge 2 $\left(\mathrm{X}_{2}\right)$ & Low Morale & 34.6 & 49.4 & 12.3 & 3.7 & 0 \\
\hline Challenge 3 $\left(\mathrm{X}_{3}\right)$ & Difficult learning at home & 40.7 & 39.5 & 17.3 & 1.2 & 1.2 \\
\hline Challenge 4 $\left(\mathrm{X}_{4}\right)$ & Unconducive at home & 29.6 & 32.1 & 27.2 & 9.9 & 1.2 \\
\hline Challenge 5 $\left(\mathrm{X}_{5}\right)$ & Lack family support & 2.5 & 11.1 & 27.2 & 39.5 & 19.8 \\
\hline Challenge 6 $\left(\mathrm{X}_{6}\right)$ & Uncertain about future studies & 42.0 & 32.1 & 14.8 & 7.4 & 3.7 \\
\hline Challenge 7 $\left(\mathrm{X}_{7}\right)$ & Fear of losing funding & 35.8 & 22.2 & 17.3 & 11.1 & 13.6 \\
\hline Challenge 8 $\left(\mathrm{X}_{8}\right)$ & Practical and research affected & 66.7 & 29.6 & 3.7 & 0 & 0 \\
\hline Challenge 9 $\left(\mathrm{X}_{9}\right)$ & Pressure to catch up & 64.2 & 33.3 & 1.2 & 1.2 & 0 \\
\hline
\end{tabular}


Table-4. Descriptive statistics.

\begin{tabular}{c|c|c}
\hline Variable & Mean & Std. deviation \\
\hline Challenge 1 & 1.346 & 0.574 \\
\hline Challenge 2 & 1.852 & 0.776 \\
\hline Challenge 3 & 1.827 & 0.848 \\
\hline Challenge 4 & 2.210 & 1.021 \\
\hline Challenge 5 & 3.630 & 1.006 \\
\hline Challenge 6 & 1.988 & 1.101 \\
\hline Challenge 7 & 2.444 & 1.423 \\
\hline Challenge 8 & 1.370 & 0.558 \\
\hline Challenge 9 & 1.395 & 0.585 \\
\hline
\end{tabular}

Table-5. Multicollinearity statistics.

\begin{tabular}{c|c|c|c}
\hline Variable & $\mathbf{R}^{\mathbf{2}}$ & Tolerance & VIF \\
\hline Challenge 1 & 0.227 & 0.773 & 1.293 \\
\hline Challenge 2 & 0.416 & 0.584 & 1.713 \\
\hline Challenge 3 & 0.400 & 0.600 & 1.668 \\
\hline Challenge 4 & 0.448 & 0.552 & 1.812 \\
\hline Challenge 5 & 0.159 & 0.841 & 1.189 \\
\hline Challenge 6 & 0.373 & 0.627 & 1.596 \\
\hline Challenge 7 & 0.188 & 0.812 & 1.231 \\
\hline Challenge 8 & 0.274 & 0.726 & 1.378 \\
\hline Challenge 9 & 0.175 & 0.825 & 1.212 \\
\hline
\end{tabular}

Table 5 and Table 6 show the multicollinearity and correlation matrix of the challenges faced by the students during the covid 19 lockdown period.

Table-6. Correlation Matrix

\begin{tabular}{|c|c|c|c|c|c|c|c|c|c|}
\hline Variables & $\begin{array}{c}\text { Challenge } \\
1\end{array}$ & $\begin{array}{c}\text { Challenge } \\
2\end{array}$ & $\begin{array}{c}\text { Challenge } \\
3\end{array}$ & $\begin{array}{c}\text { Challenge } \\
4\end{array}$ & $\begin{array}{c}\text { Challenge } \\
5\end{array}$ & $\begin{array}{c}\text { Challenge } \\
6\end{array}$ & $\begin{array}{c}\text { Challenge } \\
7\end{array}$ & $\begin{array}{c}\text { Challenge } \\
8\end{array}$ & $\begin{array}{c}\text { Challenge } \\
9\end{array}$ \\
\hline Challenge 1 & 1 & & & & & & & & \\
\hline Challenge 2 & 0.341 & 1 & & & & & & & \\
\hline Challenge 3 & 0.201 & 0.321 & 1 & & & & & & \\
\hline Challenge4 & 0.088 & 0.434 & 0.591 & 1 & & & & & \\
\hline Challenge5 & -0.057 & 0.249 & 0.246 & 0.308 & 1 & & & & \\
\hline Challenge6 & 0.205 & 0.495 & 0.279 & 0.358 & 0.222 & 1 & & & \\
\hline Challenge7 & 0.054 & 0.106 & 0.230 & 0.184 & 0.116 & 0.363 & 1 & & \\
\hline Challenge8 & 0.337 & 0.244 & 0.243 & 0.191 & -0.042 & 0.272 & 0.136 & 1 & \\
\hline Challenge9 & 0.072 & 0.213 & 0.064 & 0.090 & 0.018 & 0.163 & 0.192 & 0.351 & 1 \\
\hline
\end{tabular}

Table-7. Principal Component.

\begin{tabular}{l|c|c|c}
\hline Variables & PC1 & PC2 & PC3 \\
\hline $\mathrm{X}_{1}$ & 0.419 & -0.485 & -0.521 \\
\hline $\mathrm{X}_{2}$ & 0.721 & -0.016 & -0.240 \\
\hline $\mathrm{X}_{3}$ & 0.676 & 0.267 & -0.178 \\
\hline $\mathrm{X}_{4}$ & 0.706 & 0.378 & -0.125 \\
\hline $\mathrm{X}_{5}$ & 0.388 & 0.598 & 0.097 \\
\hline $\mathrm{X}_{6}$ & 0.704 & 0.006 & 0.158 \\
\hline $\mathrm{X}_{7}$ & 0.437 & 0.011 & 0.641 \\
\hline $\mathrm{X}_{8}$ & 0.518 & -0.584 & -0.014 \\
\hline $\mathrm{X}_{9}$ & 0.359 & -0.476 & 0.496 \\
\hline Eigenvalue & 2.886 & 1.375 & 1.069 \\
\hline Variability $\%)$ & 32.068 & 15.281 & 11.878 \\
\hline Cumulative \% & 32.068 & 47.349 & 59.227 \\
\hline
\end{tabular}

Table 7 reveals that Principal Component $1\left(P C_{t}\right)$ contributed to 32.068 percent of the variations with an eigenvalue of 2.886 in the variables included in which the cumulative percentage is 32.068 . The $\mathrm{PC}_{1}$ is strongly 
associated with 7 of the original variables. This suggests that these 7 criteria in the principal component vary together. The $P C_{l}$ increases with challenges as shown in Table 3. This suggests that the constraints and challenges faced by the students during the lockdown of Covid19 are greatly influenced by the aforementioned challenges, which can be represented as follows: $\left(P C_{1}\right)=0.4191 \mathrm{X}_{1}+0.721_{2}+0.676 \mathrm{X}_{3}+0.706 \mathrm{X}_{4}+0.704 \mathrm{X}_{6}+0.437 \mathrm{X}_{7}+$ $0.518 \mathrm{X}_{8}$.

Principal Component $2\left(P C_{2}\right)$ contributed to 15.281 percent of the variations with an eigenvalue of 1.375 in the variables included in which the cumulative percentage is 47.349. The $\mathrm{PC}_{2}$ is associated with 4 variables which can be mathematically represented as: $\left(P C_{2}\right)=-0.485 \mathrm{X}_{1}+0.598 \mathrm{X}_{5}-0.584 \mathrm{X}_{8}-0.476 \mathrm{X}_{9}$. Principal Component $3\left(P C_{s}\right)$ contributed to 11.878 percent of the variations with an eigenvalue of 1.069 included in which the cumulative percentage is 59.227. $\left(P C_{s}\right)=-0.521 \mathrm{X}_{1}+0.641 \mathrm{X}_{7}+0.496 \mathrm{X}_{9}$.

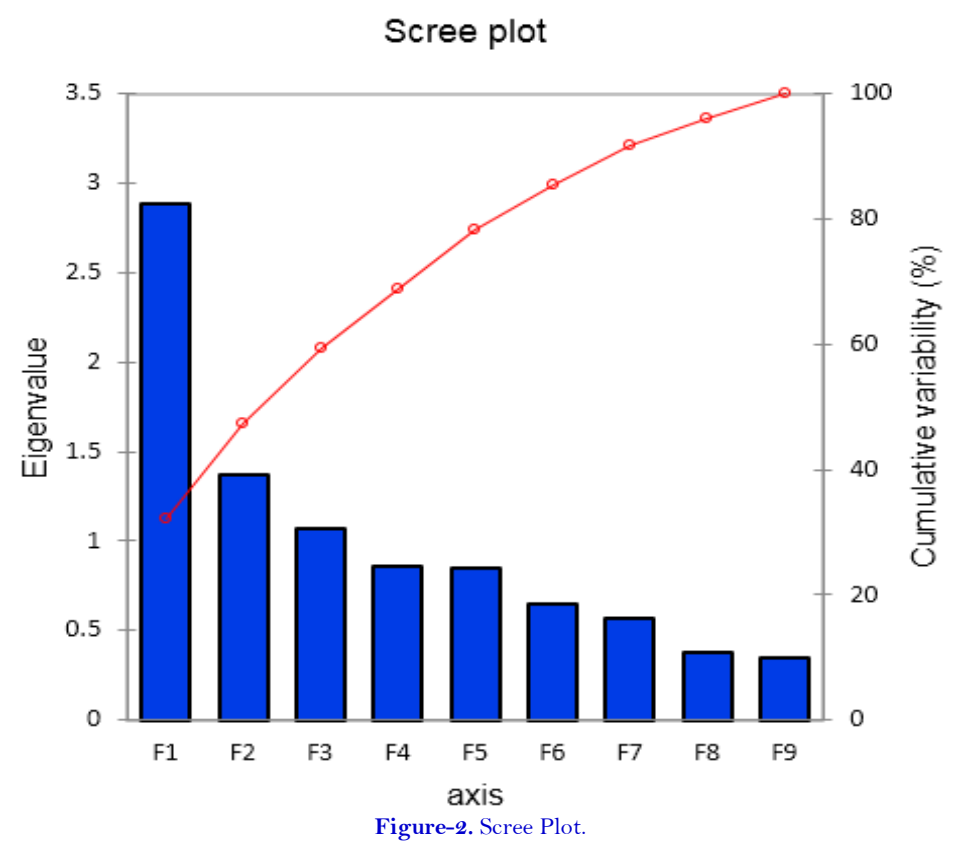

The Figure 2 shows the scree plot, which explains the eigenvalue and the cumulative variability.

Table-8. Kaiser-Meyer-Olkin measure of sampling adequacy.

\begin{tabular}{c|c}
\hline Variables (Challenges) & Values \\
\hline Challenge 1 & 0.607 \\
\hline Challenge 2 & 0.707 \\
\hline Challenge 3 & 0.705 \\
\hline Challenge 4 & 0.705 \\
\hline Challenge 5 & 0.772 \\
\hline Challenge 6 & 0.736 \\
\hline Challenge 7 & 0.632 \\
\hline Challenge 8 & 0.682 \\
\hline Challenge 9 & 0.588 \\
\hline KMO & 0.692 \\
\hline
\end{tabular}

Table 8 indicates the suitability and fitness of the PCA employed. The Kaiser-Meyer-Olkin Measure of Sampling Adequacy indicates the proportion of variance that might be caused by underlying factors. High values (close to 1) generally show that factor analysis may be useful for the data.

\subsection{Students' Willingness to Adopt E-Learning}


Findings from Figure 3 indicated that $63 \%$ of the students were unwilling to adopt E-leaning while minority $(37 \%)$ were willing to adopt it. This finding however contradicts the result in India where students readily accepted online teaching (Raju, 2020). On the contrary, a recent survey in Indonesia University of Education found mixed reaction among students, whereby $40.3 \%$ of the respondents were welcoming to E-learning. The figure below explains the willingness to adopt E-learning.

\section{Are you willing to Adopt e-learning?}

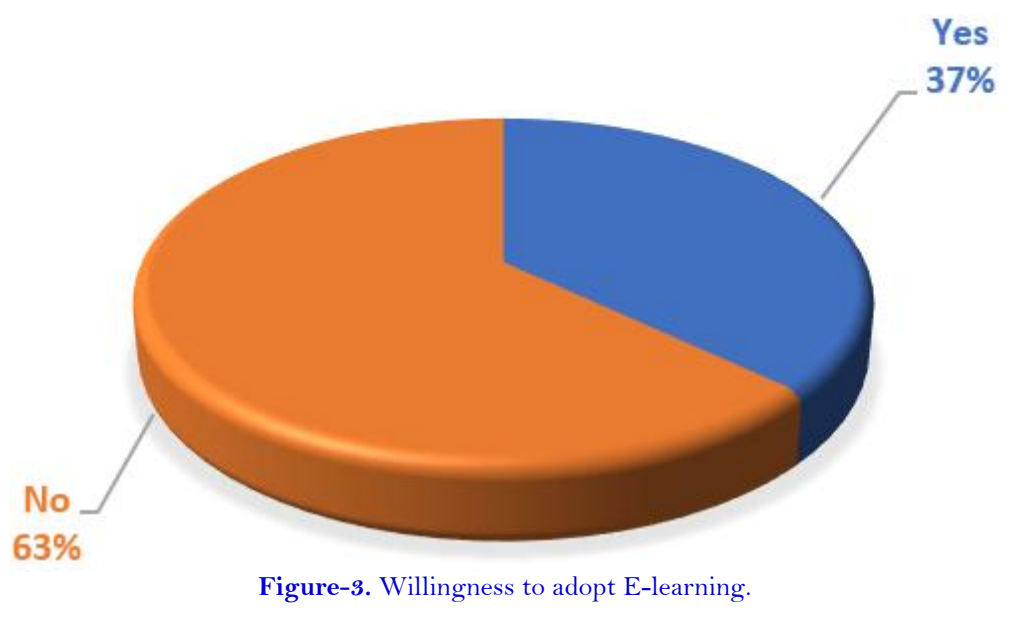

As presented in Table 9, the type of study (diploma in animal production or plant production), year of study, own smart phone, classroom teaching and student's timeline significantly influence the willingness of students to adopt E-learning.

The research shows that type of study such as Diploma in animal production or plant production is positively significant. This is because students are expected to take practical courses as part of their learning process and engaging in e-learning will only cover the theoretical part of their studies, and not the practical aspect. For example, students do not necessarily need e-learning to practicalize artificial insemination in animals, neither do plant science students have to engage in e-learning to carry out their agronomic field experiments. Rather, students can only perfect this when engaged in practical, which will make them understand their course of study better, instead of preferring e-Learning aspect only. However, it will be appropriate for students in this circumstance to engage in a hybrid mode of teaching which will comprise e-Learning and the face-to face (Agarwal \& Kumar, 2013).

Equally, this study finds that students owning smartphones are negatively significant to the study because it causes distraction (Dondorf, Breuer, \& Nacken, 2016). Students have a strong liking for social life, and they prefer using their data on social media rather than engaging themselves in online learning. They can spend unending hours on internet browsing the internet on their phones for personal reasons, but not on e-learning; although (Kumar, Kumar, \& Basu, 2002; Piccoli, Ahmad, \& Ives, 2001; Zhang, Zhao, Zhou, Nunamaker, \& Can, 2004) said benefit of E-learning are flexibility and self-controlled learning.

Level of study is positively significant because students are introduced to electronics in their first year of study which can lead to improvement in their commitment and performance academically (Carle, Jaffee, \& Miller, 2009; Roth, Ivanchenko, \& Record, 2008; Tan, 2006; Yu, Poon, \& Choy, 2006). Sometime students can be at a disadvantage because of inadequate learning approach (Byrd \& MacDonald, 2005; Sautière, Blervacq, \& Vizioli, 2019; Schmid \& Abell, 2003); they may struggle to access certain things on the internet and the application of computer skills is very crucial when writing assignments. E-learning mostly favor the 2nd and 3rd year students because they are more familiar with computer skills. 
The examination also evinces that classroom teaching is preferred because in class a lecturer can notice that a certain student is unable to comprehend his/her teaching, and as a result simplify the teaching so that the student can have a good grasp of the lecture. On the contrary, e-learning cannot reveal the level of the student's comprehension during study, unless the student informs the lecturer, or even after an examination. Besides, face to face teaching is good because students can focus on the topic at hand rather than engaging in online learning using their phones and getting distracted in their homes. The lecture room is a conducive environment for learning because once a student is in class, he/she forgets about all the troubles at home; hence the research shows that classroom learning was significantly preferred than E-learning. The study carried out by Dondorf et al. (2016) aligns with this current one, for it equally confirms that classroom learners performed significantly better than the students using the e-learning platform. Although this is contrary to the findings of Lim, Kim, Chen, and Ryder (2008), who discovered that students using the online learning platform achieved better results compared to the traditional mode of face-to-face teaching. It is also noteworthy to add that several other researchers have discovered that E-learning has become effectual in the education system in this present era, particularly with the world implementing several technologies to advance the teaching skills.

Future plans are affected more especially for the students in their last year. Different researchers concluded that students' taught process influences their process of learning (Jenkins, 2001; Jian, Sandnes, Law, Huang, \& Huang, 2009; Yin, Law, \& Chuah, 2007). Students in their last year of study just want to finish their studies and graduate.

Table-9. Marginal effects at the means (Willingness to adopt E-learning).

\begin{tabular}{|c|c|c|c|c|c|}
\hline Variables & $\begin{array}{c}\text { Marginal } \\
\text { effect }(\mathrm{dy} / \mathrm{dx})\end{array}$ & $\begin{array}{l}\text { Std. } \\
\text { Err. }\end{array}$ & $\mathbf{z}$ & $\begin{array}{l}\operatorname{Pr}> \\
\mathrm{Chi}^{2}\end{array}$ & $\begin{array}{l}\text { Odd } \\
\text { ratio }\end{array}$ \\
\hline Intercept & & 0.005 & -1.60 & 0.109 & 0.001 \\
\hline Age 1 & -0.024 & 0.019 & -1.270 & 0.209 & 0.898 \\
\hline Gender & -0.011 & 0.144 & -0.074 & 0.941 & 0.952 \\
\hline HHS 1 & 0.015 & 0.033 & 0.447 & 0.655 & 1.069 \\
\hline Settlement & 0.048 & 0.107 & 0.446 & 0.656 & 1.243 \\
\hline Diploma & 0.315 & 0.153 & 2.052 & 0.047 & 4.192 \\
\hline Level & 0.201 & 0.108 & 1.862 & 0.067 & 2.495 \\
\hline Allowance & 0.198 & 0.142 & 1.388 & 0.173 & 2.461 \\
\hline Bursary holder & 0.254 & 0.178 & 1.424 & 0.162 & 3.175 \\
\hline Smartphone & -0.511 & 0.266 & -1.922 & 0.060 & 0.098 \\
\hline Laptop & 0.073 & 0.150 & 0.490 & 0.626 & 1.397 \\
\hline E-learning will not accommodate all & -0.020 & 0.206 & -0.097 & 0.923 & 0.913 \\
\hline Difficulties with network connection & 0.175 & 0.196 & 0.893 & 0.372 & 2.217 \\
\hline The college lack enough resources for E-learning & -0.003 & 0.226 & -0.013 & 0.990 & 0.987 \\
\hline Students will not afford data for E-learning & 0.146 & 0.335 & 0.436 & 0.664 & 1.943 \\
\hline $\begin{array}{l}\text { Adjusting from full-time direct teaching to self- } \\
\text { study will be difficult }\end{array}$ & -0.304 & 0.259 & -1.174 & 0.248 & 0.251 \\
\hline I prefer classroom teaching more than online & 0.332 & 0.180 & 1.838 & 0.073 & 4.529 \\
\hline $\begin{array}{l}\text { Lockdown affects students' timeline for their future } \\
\text { plan(s) }\end{array}$ & 0.656 & 0.321 & 2.044 & 0.039 & 19.869 \\
\hline
\end{tabular}

Notes:

$\mathrm{y}=\operatorname{Pr}($ Willingness to adopt E-learning) (predict $)=0.6745005$

*, **, **** means statistically significant at the $10 \%, 5 \%$ and $1 \%$ leve $1 \mathrm{~s}$, respectively.

Number of observations $=81$.

Table 10 showed the goodness of fit, in which Cox and Snell, Nagelkerke were significant, thus, this portrayed that the model fit well fit. The Hosmer-Lemeshow test is a statistical test for goodness of fit for logistic regression models. Small p-values mean that the model is a poor fit. Like most goodness of fit tests, these small p-values (usually under 5\%) mean that your model is not a good fit. However, from the study, p-values of 0.965 shows that the model fit the very well. 
Table-10. Goodness of fit statistics (Willingness to adopt E-learning)

\begin{tabular}{|c|c|c|c|c|}
\hline \multicolumn{5}{|c|}{ Goodness of fit statistics (Willingness to adopt E-learning) } \\
\hline Statistic & & Independent & & Full \\
\hline Observations & \multicolumn{3}{|c|}{81} & 81 \\
\hline Sum of weights & \multicolumn{3}{|c|}{81.000} & 81.000 \\
\hline $\mathrm{DF}$ & \multicolumn{3}{|c|}{80} & 63 \\
\hline -2 Log (Likelihood) & \multicolumn{3}{|c|}{106.783} & 84.392 \\
\hline $\mathrm{R}^{2}$ (McFadden $)$ & \multicolumn{3}{|c|}{0.000} & 0.210 \\
\hline $\mathrm{R}^{2}(\mathrm{Cox}$ and Snell $)$ & \multicolumn{3}{|c|}{0.000} & 0.242 \\
\hline $\mathrm{R}^{2}$ (Nagelkerke) & \multicolumn{3}{|c|}{0.000} & 0.330 \\
\hline $\mathrm{AIC}$ & \multicolumn{3}{|c|}{108.783} & 120.392 \\
\hline SBC & \multicolumn{3}{|c|}{111.177} & 163.492 \\
\hline Iterations & \multicolumn{3}{|c|}{$\mathrm{O}$} & 12 \\
\hline \multicolumn{5}{|c|}{ Test of the null hypothesis Ho: $\mathrm{Y}=0.630$ (Willingness to adopt E-learning): } \\
\hline Statistic & DF & Chi-square & & $\operatorname{Pr}>\mathrm{Chi}^{2}$ \\
\hline -2 Log (Likelihood) & 17 & 22.391 & & 0.170 \\
\hline Score & 17 & 19.648 & & 0.293 \\
\hline Wald & 17 & 15.253 & & 0.577 \\
\hline \multicolumn{5}{|c|}{ Hosmer-Lemeshow test (Willingness to adopt E-learning): } \\
\hline \multicolumn{2}{|c|}{ Statistic } & Chi-square & $\mathrm{DF}$ & $\operatorname{Pr}>\mathrm{Chi}^{2}$ \\
\hline \multicolumn{2}{|l|}{ Hosmer-Lemeshow Statistic } & 2.982 & 9 & 0.965 \\
\hline
\end{tabular}

ROC Curve (AUC=0.800)

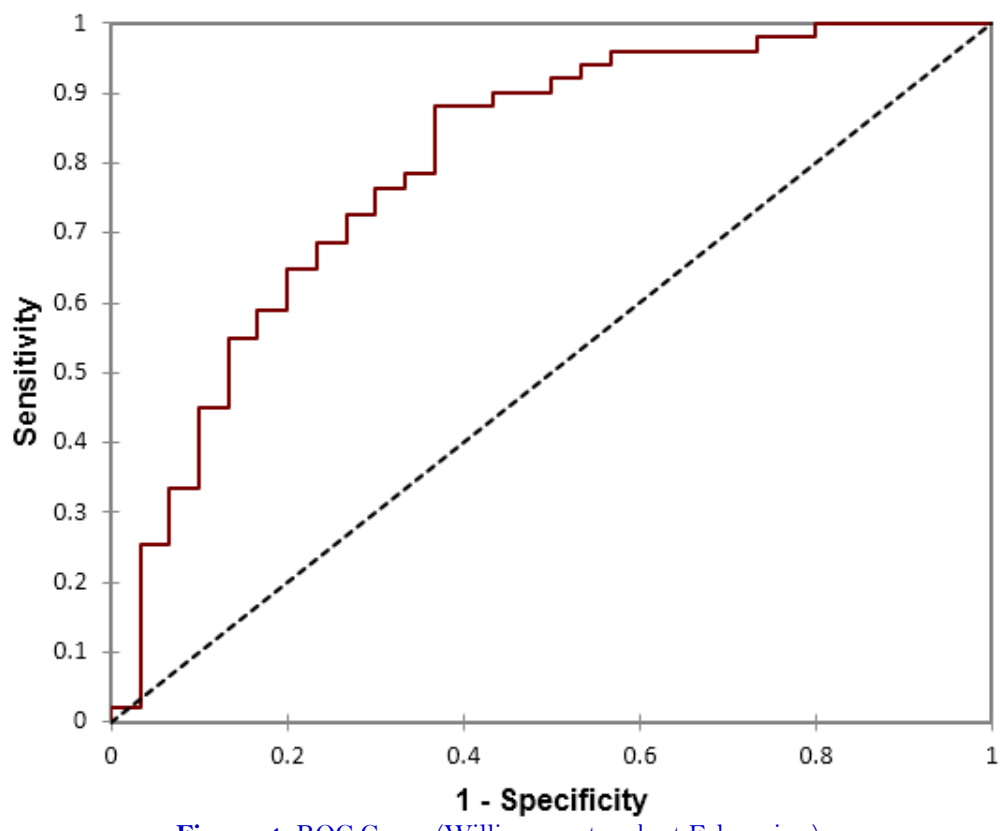

Figure-4. ROC Curve (Willingness to adopt E-learning).

As shown in Figure 4, the areas under ROC curve are used to compare the usefulness of test. The (AUC) area under the curve: 0.8 considered excellent is what denotes that the model fits the variables well.

\section{CONCLUSION AND RECOMMENDATION}

This paper has carried out a research on the implications and challenges of lockdown in the educational system by focusing on Tompi Seleka College of Agriculture in South Africa, a tertiary institution, and the possibility of adopting e-learning as a channel of teaching and learning. The research indicates that coronavirus pandemic has 
disrupted the education of many agricultural students, which can appropriately mirror the same situation in every affected country. This is especially so because the introduction of lockdown meant students had to move away from their learning institutions to their homes. The uncertainty as to when the lockdown will end triggered institutions into finding alternative means and approaches to continue learning. Hence, taking courses online (E-learning) which is considered as an alternative to face-to-face lecture has been adopted as the sui generis solution to imparting knowledge. However, the analysis shows that only $37 \%$ of the students interviewed are willing to adopt e-learning, which is just a minority of the students. The identified constraints and challenges influencing the unwillingness of students to adopting e-learning include the use of smartphone, classroom preference to online, and the student's level of study, among others. However, in order to stimulate students' adoption of e-learning as a profitable way of teaching and learning, the study recommends that colleges should strive to strengthen online teaching not only during the pandemic but also as their new and alternative to traditional way of learning particularly for non-practical modules. Additionally, infrastructure such as internet should be improved upon and provision of devices for smart learning for students which must be used for the intended purpose of learning. Moreover, the awareness and importance of E-learning should be promoted. Above all, a conducive, friendly, and smart environment which supports online learning should be instituted.

Funding: This study received no specific financial support.

Competing Interests: The authors declare that they have no competing interests.

Acknowledgement: All authors contributed equally to the conception and design of the study.

\section{REFERENCES}

Agarwal, H., \& Kumar, A. (2013). E-learning for agriculture education in India. International Journal of Research in Engineering and Technology, 2(12), 101-105. Available at: https://doi.org/10.15623/ijret.2013.0212017.

Byrd, K. L., \& MacDonald, G. (2005). Defining college readiness from the inside out: First-generation college student perspectives. Community College Review, 33(1), 22-37. Available at: https://doi.org/10.1177/009155210503300102.

Carle, A. C., Jaffee, D., \& Miller, D. (2009). Engaging college science students and changing academic achievement with technology: A quasi-experimental preliminary investigation. Computers $\mho^{2}$ Education, 52(2), 376-380. Available at: https://doi.org/10.1016/j.compedu.2008.09.005.

Dondorf, T., Breuer, R., \& Nacken, H. (2016). Classroom Vs. E-learning: A case study on the performance of students in different learning scenarios. Paper presented at the Conference Paper.

Gedye, L. (2020). Covid-19 turns learning into costly data exercise. New Frame, 3 Apr. 2020. Retrieved from: www.newframe.com/covid-19-turns-learning-into-costly-data-exercise/.

Jain, K., \& Mohta, S. (2019). The impact of home environment on academic achievement of secondary school students. International Journal of Trend in Scientific Research and Development, 3(4), 808-811. Available at: 10.31142/ijtsrd23910.

Jenkins, T. (2001). The motivation of students of programming. ACM SIGCSE Bulletin, 33(3), 53-56. Available at: $10.1145 / 507758.377472$.

Jian, H. L., Sandnes, F. E., Law, K. M., Huang, Y. P., \& Huang, Y. M. (2009). The role of electronic pocket dictionaries as an English learning tool among Chinese students. Journal of Computer Assisted Learning, 25(6), 503-514. Available at: https://doi.org/10.1111/j.1365-2729.2009.00325.x.

Koutsoyiannis, A. (1979). Linear programming. In: Modern microeconomics. London: Palgrave.

Kumar, A., Kumar, P., \& Basu, S. C. (2002). Student perceptions of virtual education: An exploratory study, in Web-based instructional learning, M. Khosrowpour, Ed, Hershey, Pa (pp. 132-141): IRM Press.

Lim, J., Kim, M., Chen, S. S., \& Ryder, C. E. (2008). An empirical investigation of student achievement and satisfaction in different learning environments. Journal of Instructional Psychology, 35(2), 113-119.

Oduniyi, O. S. (2018). Implication of climate change on livelihood and adaptation of small and emerging maize farmers in the North West Province of South Africa. PhD Thesis, University of South Africa. 
Pelmin, M. (2020). Readings on coronavirus disease (COVID-19) and the higher education institution (HEIs) emergency preparedness in the Philippines (April 12, 2020). Available at SSRN: https://ssrn.com/abstract=3573896 or http://dx.doi.org/10.2139/ssrn.3573896.

Piccoli, G., Ahmad, R., \& Ives, B. (2001). Web-based virtual learning environments: A research framework and a preliminary assessment of effectiveness in basic IT skills training. MIS Quarterly, 25(4), 401-426. Available at: https://doi.org/10.2307/3250989.

Raju, H. (2020). Covid -19 lockdown-challenges to higher education. Dr. AIT, ECE Bengaluru,(ongoing project), 20944.

Roth, V., Ivanchenko, V., \& Record, N. (2008). Evaluating student response to WeBWorK, a web-based homework delivery and grading system. Computers $\Theta^{\circ}$ Education, $50(4), \quad$ 1462-1482. Available at: https://doi.org/10.1016/j.compedu.2007.01.005.

Sautière, P.-E., Blervacq, A.-S., \& Vizioli, J. (2019). Production and uses of e-learning tools for animal biology education at University. The European Zoological Journal, 86(1), 63-78. Available at: https://doi.org/10.1080/24750263.2019.1582722.

Schmid, C., \& Abell, P. (2003). Demographic risk factors, study patterns, and campus involvement as related to student success among Guilford Technical Community College students. Community College Revierw, 31(1), 1-16. Available at: https://doi.org/10.1177/009155210303100101.

StatsSA (Statistics South Africa). (2008). Community survey 2007. Pretoria: Statistics South Africa.

Tan, O. S. (2006). Development of a thinking programme for engineering students. Innovations in Education and Teaching International, 43(3), 245-259. Available at: https://doi.org/10.1080/14703290600618530.

UNESCO. (2020). Adverse consequences of school closures. UNESCO. 2020-03-10. Retrieved 2020-03-15.

World Tourism Organization. (2020). 2019-nCoV situation report. Retrieved from: https:// www.who.int/emergencies/diseases/novel-coronavirus-2019/situationreports/. [Accessed February 7, 2020].

Yin, Y. T., Law, M. Y. K., \& Chuah, K. B. (2007). Investigation of the motivating factors influencing team learning. Paper presented at the Proceedings of the 5 th International Symposium on Management of Technology (CD Rom).

Yu, Y. T., Poon, C. K., \& Choy, M. (2006). Experiences with PASS: Developing and using a Programming Assignment assessment System. Paper presented at the In Proceedings of QSIC 2006: The 6th International Conference On Quality Software.

Zhang, D., Zhao, J., Zhou, L., Nunamaker, J., \& Can, E. (2004). E-learning replace classroom learning? Communications of the ACM, 47(5), 75-79. Available at: https://doi.acm.org/10.1145/986213.986216.

\section{APPENDIX}

Table-A. Bartlett's sphericity test.

\begin{tabular}{l|c}
\hline Chi-square (Observed value) & 141.684 \\
\hline Chi-square (Critical value) & 50.998 \\
\hline DF & 36 \\
\hline p-value (Two-tailed) & 0.0000 \\
\hline Alpha & 0.05 \\
\hline Note: Small values (less than 0.05) of the significance level shown in Table A indicates that factor analysis may be useful with the data.
\end{tabular}

Appendix A explained the suitability of the Principal Component Analysis employed to explain the challenges experienced by the students during the Covid-19 lockdown. This Bartlett's sphericity test actually complements the Kaiser-Meyer-Olkin Measure of Sampling Adequacy.

Views and opinions expressed in this article are the views and opinions of the author(s), International Journal of Asian Social Science shall not be responsible or answerable for any loss, damage or liability etc. caused in relation to/arising out of the use of the content. 
International Journal of Asian Social Science, 2021, 11(7): 300-313 